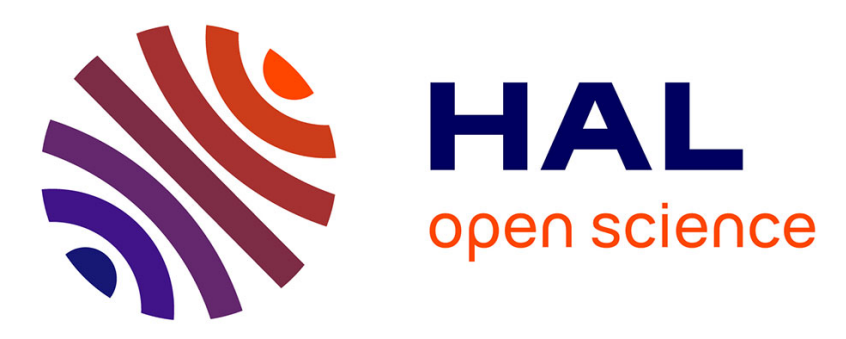

\title{
New Cobalt-Bisterpyridyl Catalysts for Hydrogen Evolution Reaction
}

Safwan Aroua, Tanya K Todorova, Victor Mougel, Paul Hommes, Hans

Reissig, Marc Fontecave

\section{- To cite this version:}

Safwan Aroua, Tanya K Todorova, Victor Mougel, Paul Hommes, Hans Reissig, et al.. New Cobalt-Bisterpyridyl Catalysts for Hydrogen Evolution Reaction. ChemCatChem, 2017, 10.1002/cctc.201700428 . hal-01522600

\section{HAL Id: hal-01522600 https://hal.sorbonne-universite.fr/hal-01522600}

Submitted on 15 May 2017

HAL is a multi-disciplinary open access archive for the deposit and dissemination of scientific research documents, whether they are published or not. The documents may come from teaching and research institutions in France or abroad, or from public or private research centers.
L'archive ouverte pluridisciplinaire HAL, est destinée au dépôt et à la diffusion de documents scientifiques de niveau recherche, publiés ou non, émanant des établissements d'enseignement et de recherche français ou étrangers, des laboratoires publics ou privés. 


\title{
New Cobalt-Bisterpyridyl Catalysts for Hydrogen Evolution Reaction
}

\author{
Safwan Aroua, ${ }^{[a]}$ Tanya K. Todorova, ${ }^{[a]}$ Victor Mougel, ${ }^{[a]}$ Paul Hommes, ${ }^{[b]}$ Hans-Ulrich Reissig, ${ }^{[b]}$ Marc \\ Fontecave ${ }^{*[a]}$
}

\begin{abstract}
Preparation of a series of terpyridyl ligands bearing different substituents recently led to the synthesis of new cobaltbisterpyridyl complexes spanning over a wide range of redox potentials. In this work, we describe the catalytic properties of these complexes for the electroreduction of protons into hydrogen (HER) in acetonitrile. The substituents of the ligands were found to greatly affect the catalytic performances of the systems, in terms of stability and overpotential. Interestingly, systems based on dimethylaminoterpyridine derivatives perform HER with high efficiency, low overpotential and excellent stability. Density functional theory calculations were used to provide insights into the reaction mechanism of HER catalyzed by these systems, highlighting the role of the ligand for proton activation.
\end{abstract}

Major efforts are currently spent into the development of green energy technologies based on solar and wind power. However these energy sources suffer from low energetic density and intermittency. To overstep such failings, a common approach involves their storage by conversion into chemical energy via the formation of chemical bonds. Best examples of these strategies are the photochemical or electrochemical reduction of protons $\left(2 \mathrm{H}^{+}\right)$to molecular hydrogen $\left(\mathrm{H}_{2}\right)$, allowing energy storage via the formation of an $\mathrm{H}-\mathrm{H}$ chemical bond. ${ }^{[1-3]}$ The kinetic barrier for such transformation is large and hence catalysts are required to lower it. While metallic platinum remains the most effective catalytic material for the hydrogen evolution reaction (HER), its limited availability and high cost justifies the quest for alternative catalysts based on non-noble metals, cheaper and abundant. Current research focuses primarily on two types of compounds: solid materials and homogeneous metal complexes. Despite being more complex than heterogeneous materials, molecular catalysts are often ideal for fine tuning reactivity via synthetic modifications of the ligands. In this context, significant success has been recently obtained with molecular cobalt complexes, in particular cobaloximes, cobalt-diimine-dioximes and cobalt-polypyridine complexes. ${ }^{[3-7]}$ The latter have the remarkable ability to store multiple reducing equivalents, since the ligand not only stabilizes the reduced metal center but also accumulates reducing equivalents within its $\pi$-conjugated system. Within this class of compounds, our group has investigated the yet rarely studied potential of simple and cheap cobalt-bisterpyridine complexes as

\footnotetext{
[a] Dr. Safwan Aroua, Dr. Tanya K. Todorova, Dr. Victor Mougel, Prof. Marc Fontecave

Laboratoire de Chimie des Processus Biologiques, Collège de France, 11 Place Marcelin Berthelot,75231 Paris Cedex 05 (France) marc.fontecave@college-de-france.fr

[b] Dr. Paul Hommes, Prof. Hans-Ulrich Reissig Institut für Chemie und Biochemie, Freie Universität Berlin, Takustrasse 3, 14195 Berlin (Germany)

Supporting information for this article is given via a link at the end of
} the document. catalysts for $\mathrm{CO}_{2}$ and proton reduction. ${ }^{[8]}$ In particular, we have shown that these complexes can be grafted at the surface of glassy carbon electrodes, on which they display significant HER activity. ${ }^{[9]}$ To optimize such catalysts, we have synthesized a variety of new terpyridines with different substituents (very few functionalized terpyridine derivatives were commercially available). Synthesis and characterization of the corresponding cobalt complexes $(\mathbf{C} \mathbf{1}-\mathbf{C} 8 \text { in Figure } 1)^{1}$ thus allow building structure-activity relationship studies with respect to HER catalysis. Here we show that $\mathbf{C 2}$ and $\mathbf{C 8}$ complexes based on dimethylamino-terpyridines are the most efficient catalysts, working at relatively low overpotential and displaying good faradaic yields and excellent stability.

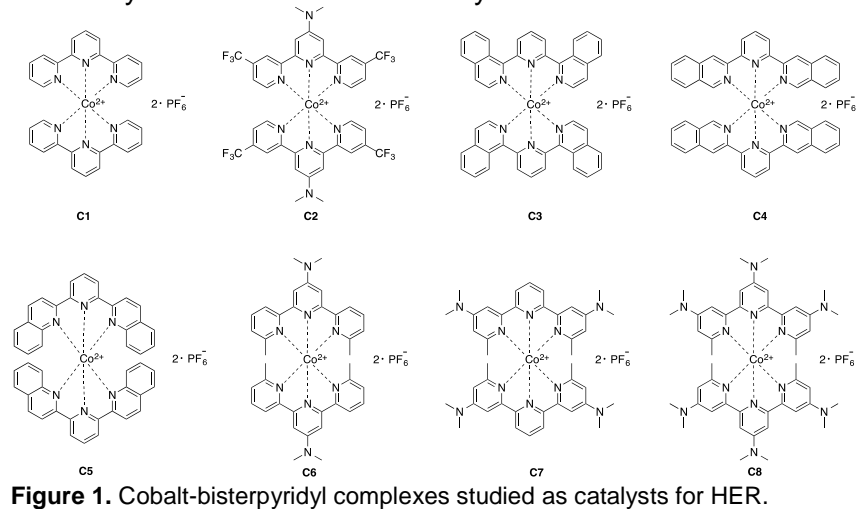

Eight cobalt complexes (C1 - C8 in Figure 1) have been prepared as previously described and electrochemically characterized. ${ }^{[10]} \mathbf{C} 1$ is the prototypic complex of this family and has no functionalization of the terpyridine ligand. C3, C4 and C5 contain quinoline or isoquinoline moieties within the ligand. We previously characterized these complexes by Cyclic Voltammetry (CV). ${ }^{[10]}$ We observed that the position of the phenyl ring of the (iso)quinoline has a strong influence on the electronics of the ligands and thus on the redox potentials of the complexes (see below): in C3 and C5, the (iso)quinoline unit is less electron-donating than a single pyridine, while in $\mathbf{C 4}$ it is more, as deduced from the comparison with the CV of C1. C6, C7 and C8 bear strongly electron-donating dimethylamino substituents (central position in $\mathbf{C 6}$, distal positions in $\mathbf{C 7}$, central and distal positions in $\mathbf{C 8}$ ), while $\mathbf{C 2}$ combines electron-donating (dimethylamino in central position) and electron-withdrawing (trifluoromethyl in distal positions) groups. The CVs of the complexes $\mathbf{C 1}$ - $\mathbf{C 8}$ recorded in acetonitrile in the absence and

C1: $\quad\left[\mathrm{Co}\left(2,2^{\prime}: 6^{\prime}, 2^{\prime \prime} \text {-terpyridine }\right)_{2}\right] .2 \mathrm{PF}_{6} ; \quad$ C2: $\quad\left[\mathrm{Co}\left(4,4^{\prime \prime}\right.\right.$-trifluoromethyl-4'dimethylamino-2,2':6',2"-terpyridine) 2 ].2PF $\mathrm{F}_{6} ; \quad$ C3: [Co(2,6-di(isoquinolin-1yl)pyridine) $\left.)_{2}\right] .2 \mathrm{PF}_{6} ; \quad \mathbf{C 4}$ : $\quad\left[\mathrm{Co}\left(2,6-\mathrm{di}\left(\right.\right.\right.$ isoquinolin-3-yl)pyridine) $\left.{ }_{2}\right] .2 \mathrm{PF}_{6} ; \quad \mathbf{C 5}$ : [Co(2,6-di(quinolin-2-yl)pyridine $\left.)_{2}\right] .2 \mathrm{PF}_{6} ; \quad$ C6: [Co(2,2"-methyl-4'dimethylamino-2,2':6',2"-terpyridine) 2 ].2PF 6 ; C7: [Co(4,4"-dimethylamino-2,2"methyl-2,2':6',2"-terpyridine $\left.)_{2}\right] .2 \mathrm{PF}_{6} ; \quad \mathbf{C 8}$ : [Co(4,4',4"-dimethylamino-2,2"methyl-2,2':6',2"-terpyridine) 2$] .2 \mathrm{PF}_{6}$ 
in the presence of acetic acid (10 equiv.) are displayed in Figure 2. Acetic acid was chosen as a proton source for its low pKa value in organic media $\left(23.5\right.$ in $\left.\mathrm{CH}_{3} \mathrm{CN}\right),{ }^{[11-12]}$ and for its very cathodic reduction potential on a bare glassy carbon electrode, allowing CVs to be virtually unaffected by background $\mathrm{H}^{+}$ reduction at the electrode (at the potentials used in this study). ${ }^{[12]}$ Because of the very negative potential for HER in acetonitrile ( $E^{0}$ $\left(\mathrm{H}^{+} / \mathrm{H}_{2}\right)=-1.26 \mathrm{~V}$ vs. $\mathrm{Fc}^{+} / \mathrm{Fc}$ at $\left.10 \mathrm{mM} \mathrm{AcOH}\right),{ }^{[11]}$ the potentials were scanned down to the second one-electron reduction. Indeed, in the absence of acid (black curves in Figure 2), the CVs were all similar with two one-electron reduction features. The first one has been assigned to a metal-based (Coll/Co') process and the second more cathodic feature to a ligand-based (tpy/tpy ${ }^{\circ}$ ) one..$^{[10]}$ While the first feature is reversible in all cases, the second one shows some irreversibility in the case of $\mathbf{C 2}$ and C4. On the other hand, the electronic properties of the ligand have a drastic effect on the redox potentials, which span over a broad range of almost $1 \mathrm{~V}$, from complex $\mathbf{C} 3$, with the more electron-withdrawing ligand, to complex $\mathbf{C 8}$, with the more electron-donating ligand.

In all cases, upon addition of acetic acid (red curves in Figure 2), one (or two) catalytic wave(s) was observed corresponding to proton reduction to $\mathrm{H}_{2}$, as shown by bulk electrolysis experiments (see below), thus demonstrating that C1 - C8 were all catalytically active. However significant differences between the studied complexes were observed in terms of onset potential, peak current density enhancement and stability. With $\mathbf{C 1}-\mathbf{C 7}$, catalysis occurred at a potential more cathodic than that of the first one-electron metal-based reduction event, which remained essentially unaffected by the addition of acid. While with $\mathbf{C 1}$ - C5 the catalytic peak occurred approximately at the potential of the ligand-based redox feature, the onset potentials were significantly more anodic in the case of C1, C2 and C4. Such a shift might indicate that after a first oneelectron reduction step (reduction of the metal center), the second electron transfer step is proton-coupled, during which reduction of the ligand is assisted by protonation. This was much less pronounced in the case of $\mathbf{C} \mathbf{3}$ and $\mathbf{C 5}$, which have the highest redox potentials, reflecting the strongest electronwithdrawing properties of the terpyridyl ligands. Thus, onset potentials were $-1.6 \mathrm{~V}$ for the reference complex $\mathbf{C 1}(\eta=350$ $\mathrm{mV}),-1.55 \mathrm{~V}(\eta=300 \mathrm{mV})$ for $\mathbf{C 2},-1.5 \mathrm{~V}(\eta=250 \mathrm{mV})$ for $\mathbf{C 3}$ and $\mathbf{C 5}$, and $-1.7 \mathrm{~V}(\eta=450 \mathrm{mV})$ for $\mathbf{C 4}$.

Finally, in the case of $\mathbf{C 6}$ and $\mathbf{C} 7$ two catalytic waves were observed, one at $\approx-2 \mathrm{~V}$, in between the two one-electron redox features, and the other one approximately at the potential of the second feature (Figure 2). In contrast to $\mathbf{C 1}-\mathbf{C 7}$, catalysis occurred at a potential more anodic than the metal-based feature with $\mathbf{C 8}$, and about $1 \mathrm{~V}$ more anodic than that of the ligand-based reduction (in the absence of acid). Thus, in spite of the strong electron-donating properties of the ligands containing dimethylamino groups and the very negative redox potentials of the corresponding complexes in the absence of acid, HER catalytic onset potentials are among the most positive within this class of complexes, at $-1.5 \mathrm{~V}(\eta=250 \mathrm{mV})$, as facilitated by protonation of the catalyst. To probe if, in the case of $\mathbf{C 8}$, protonation occurs before the first one-electron reduction, a titration experiment was performed by adding increasing equivalents of acetic acid to a solution of complex $\mathbf{C 8}$. No light absorption spectrum change could be observed after addition of up to 100 equiv. (Figure S1d), suggesting that a first reduction is required to allow protonation of the system. This experiment also indicated the excellent stability of $\mathbf{C 8}$ in the presence of acid in excess. Similar stability was observed for the other complexes bearing dimethylamino substituents (C2, C6 and C7): their UVvis spectra remained unchanged upon addition of 100 equiv. acetic acid (Figure S1a-c).

In fact the behavior of $\mathbf{C 8}$ is unique only because a weak acid is used in these experiments. Under such conditions $\mathbf{C 8}$ is the only complex of the series basic enough to allow $\mathrm{H}_{2}$ evolution at a potential more positive than that of the metalbased feature. As a matter of fact, in the case of $\mathbf{C 7}$, a less basic complex, the first catalytic wave shifted anodically upon increasing the strength of the acid (phenol, pKa 29.1; acetic acid, pKa 23.5; benzoic acid, pKa 21.5; salicylic acid, pKa 16.7). With the stronger acid, the onset potential thus became more positive than the potential of the metal-based feature, as observed in the case of $\mathbf{C 8}$ in the presence of acetic acid (Figure S9). Thus different mechanisms are operating, depending on the pKa of the acid as previously observed in the case of cobaloximes. ${ }^{[6]}$

The CVs shown in Figure 2 also gave some insight into the relative efficiencies of the cobalt complexes, as probed by the current density enhancement $\left(i / i_{p}\right)$ upon addition of $10 \mathrm{mM}$ acetic acid. Clearly, C3 and C5 proved much less efficient than the other complexes. This is consistent with the electronwithdrawing character of the ligands. Based on the $i / i_{p}$ parameter, complexes $\mathbf{C 2}$ and $\mathbf{C} 4$ proved the most active catalysts while $\mathbf{C 6}$, $\mathbf{C 7}$ and $\mathbf{C 8}$ were comparable to $\mathbf{C} \mathbf{1}$.
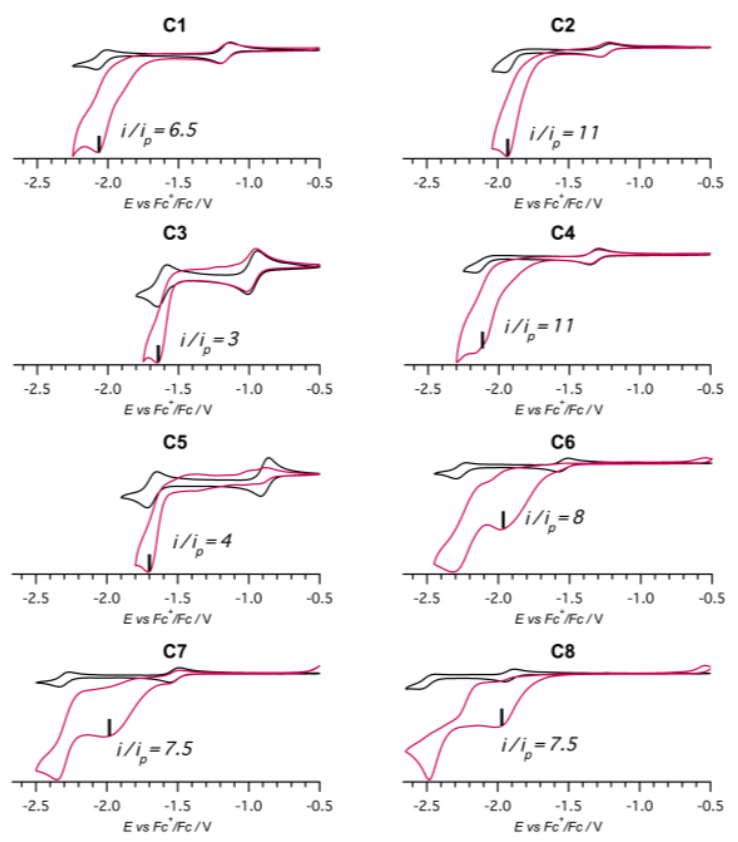

Figure 2. $\mathrm{CV}$ for the complexes $\mathbf{C} 1-\mathbf{C 8}\left(1.0 \mathrm{mM}\right.$, in black) in $\mathrm{CH}_{3} \mathrm{CN}(50$ $\mathrm{mV} / \mathrm{s}, 0.1 \mathrm{TBAP})$, and in the presence of acetic acid $\left(10 \mathrm{mM}\right.$, in red). $i / i_{p}$ values for the first catalytic wave are indicated. 


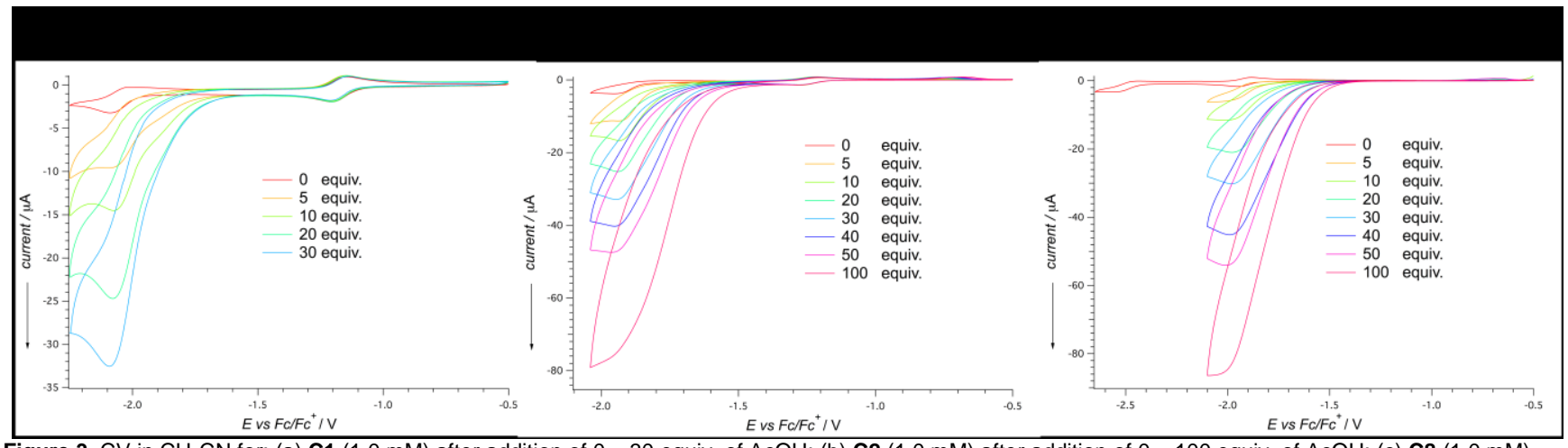

Figure 3. $\mathrm{CV}$ in $\mathrm{CH}_{3} \mathrm{CN}$ for: (a) $\mathbf{C 1}(1.0 \mathrm{mM}$ ) after addition of $0-30$ equiv. of $\mathrm{AcOH}$; (b) $\mathbf{C 2}$ (1.0 mM) after addition of $0-100$ equiv. of $\mathrm{AcOH}$; (c) $\mathbf{C 8}$ (1.0 mM) after addition of $0-100$ equiv. of $\mathrm{AcOH}$.

Finally, the stability of complexes $\mathbf{C} \mathbf{1}-\mathbf{C} 8$ was assessed by monitoring the behavior of the metal-based redox feature upon addition of increasing amounts of acetic acid (Figure 3 and Figures S2-S8). In the case of complex $\mathbf{C 1}$, this feature was conserved up to $30 \mathrm{mM}$ of acid but disappeared at $40 \mathrm{mM}$ (Figure S2), suggesting decomposition of the complex. In contrast, this feature was conserved at all investigated acid concentrations (up to $100 \mathrm{mM}$ ) in the case of C2 (Figure 3) and C3 (Figure S3), demonstrating their greater stability. Complexes C4, C5 and C6 were highly acid-sensitive and unstable, as indicated by the disappearance of the metal-based feature (at $1.35 \mathrm{~V}$ for $\mathbf{C 4},-0.89 \mathrm{~V}$ for $\mathbf{C 5}$ and $-1.6 \mathrm{~V}$ for $\mathbf{C 6}$ ) at acetic acid concentrations above $10 \mathrm{mM}$ (Figure S4-S6).

Since the catalytic wave masked the metal-based feature in the CVs, the latter could not be used for assessing the stability of complexes C7 (Figure S7) and C8 (Figure 3 and Figure S8). Nevertheless the continuous increase of the catalytic wave upon addition of up to 100 equivalents acid indicated a good stability of $\mathbf{C 8}$ (Figure 3 ).

Based on the above considerations, namely the onset potentials, current enhancement and stability, we have selected three catalysts for further characterization: $\mathbf{C 2}$ for its stability and efficiency, C3, in spite of its limited activity, for its stability and its low onset potential and $\mathbf{C 8}$ for its efficiency, stability and low onset potential. As shown in Figures S10-S13 the three Co"/Co reduction waves are diffusion controlled, with a difference between the potential of the anodic and cathodic peaks (peakto-peak separation) of about $60 \mathrm{mV}$ at slow scan rates (typically $50 \mathrm{mV} / \mathrm{sec}$ ) and with the peak-to-peak separation increasing as the scan rate increased. Accordingly, the plots of $i_{p c}$ and $i_{p a} v s$. $v^{1 / 2}$ were linear and the $i_{p a} / i_{p c}$ ratio was close to unity in the 50 $2000 \mathrm{mV} / \mathrm{sec}$ scan rate range (insets of Figure S10-S13). (a)

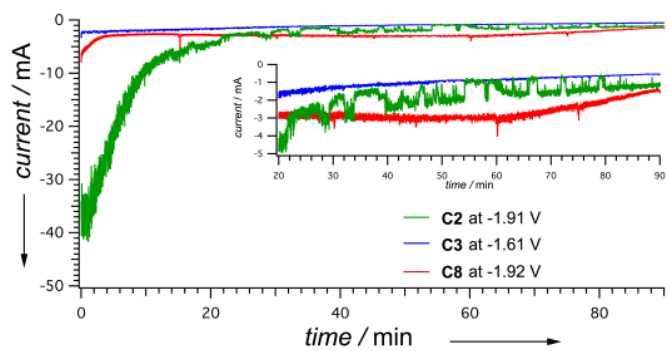

Furthermore, with catalysts C2, C8, and also C1, a linear increase of the catalytic current occurred with the increase of the concentration of acetic acid (Figures S14, S17, S21). This was not the case with $\mathbf{C 3}$ for which the catalytic current intensity levelled off after addition of $20 \mathrm{mM}$ acetic acid (Figure S20).

While fraught with limitations and generally leading to underestimated TOF values, we used the $i_{c} / i_{p}$ analysis with the purpose of estimating the hydrogen evolution kinetics by cyclic voltammetry in the case of complexes $\mathbf{C 1}, \mathbf{C 2}$ and $\mathbf{C 8}$. The $i_{c} i_{p}$ analysis, described more in detail elsewhere ${ }^{[13-15]}$ and in the supplementary section (Figures S15, S16, S18, S19, S22, S23), allowed us to determine a TOF value in $0.1 \mathrm{M}$ acetic acid of 705 $\mathrm{s}^{-1}$ at $-2.04 \mathrm{~V}$ for $\mathbf{C 1}, 1445 \mathrm{~s}^{-1}$ at $-1.91 \mathrm{~V}$ for $\mathbf{C 2}$, and $415 \mathrm{~s}^{-1}$ at $1.92 \mathrm{~V}$ for $\mathbf{C 8}$, demonstrating the greater performance of $\mathbf{C 2}$ over $\mathbf{C} 8$ and $\mathbf{C} 1$. We could not determine the TOF value for $\mathbf{C 3}$ but obviously a much lower value is expected.

Bulk electrolysis experiments were then performed during 90 minutes using C2, C3 and C8 at a concentration of $1.0 \mathrm{mM}$ on a mercury pool electrode, in the presence of $0.1 \mathrm{M}$ acetic acid (Figure 4, details in ESI). The applied potential was chosen to be the one giving the highest catalytic current observed by $\mathrm{CV}$ (-1.91 V for C2, $-1.61 \mathrm{~V}$ for $\mathbf{C} 3$ and $-1.92 \mathrm{~V}$ for $\mathbf{C 8})$. Complex $\mathbf{C 1}$ was not studied, because of its limited stability (decomposition above $30 \mathrm{mM}$ of $\mathrm{AcOH}$ ). Hydrogen formation over time was monitored by gas chromatography during electrolysis. The data are shown in Figure 4 and in Figures S25-S27. In all cases, the decrease of the current over time reflected substrate consumption rather than catalyst inactivation, as shown by the addition of a second aliquot of acid, which allowed the reaction to resume with kinetics comparable to the initial one (Figures S25-S27).

(b)

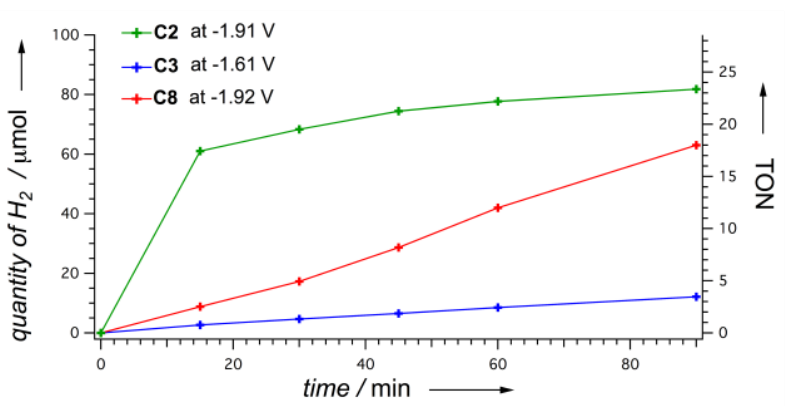

Figure 4. (a) CPE experiment for $\mathbf{C 2}$ at $-1.91 \mathrm{~V}, \mathbf{C} 3$ at $-1.65 \mathrm{~V}$ and $\mathbf{C 8}$ at $-1.95 \mathrm{~V}$; (b) Hydrogen evolution measured in the headspace of the cell over time for $\mathbf{C 2}$ C3 and C8. 


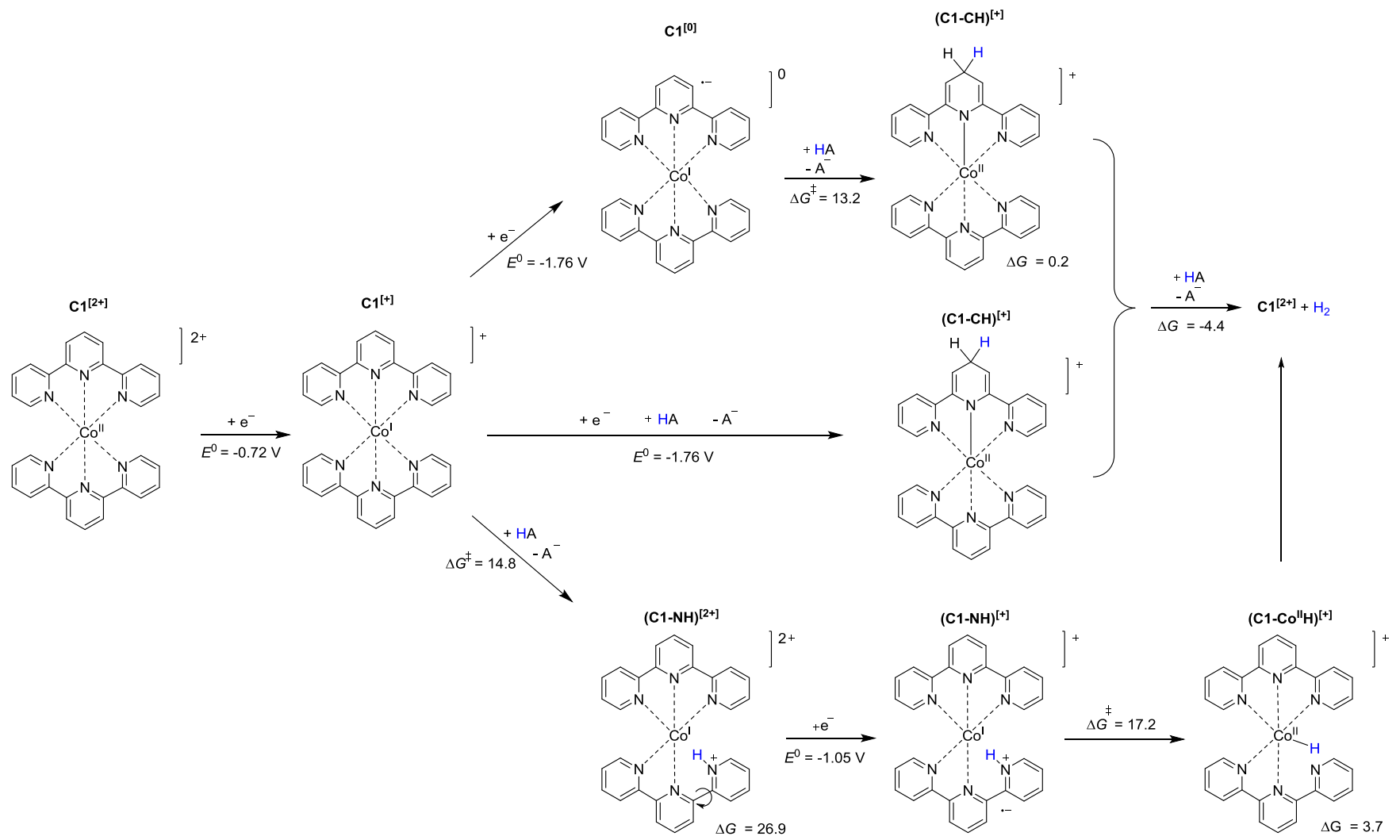

Figure 5. Proposed reaction mechanism for hydrogen evolution by complex $\mathbf{C} 1$. The relative Gibbs free energies of protonation $\left(\Delta G\right.$, kcal mol $\left.{ }^{-1}\right)$ are computed using the homoconjugated acetic acid couple and the standard one-electron reduction potentials $\left(E^{0}, \mathrm{~V}\right)$ are given $v s$. $\mathrm{Fc}_{\mathrm{c}} / \mathrm{Fc}^{+} . \Delta \mathrm{G}^{\ddagger}$ are the transition state barriers computed with an acetic acid molecule as an explicit proton source.

In the case of $\mathbf{C 3}$, a low current (below $2 \mathrm{~mA}$ ) was measured, during electrolysis with a low faradaic yield of $42 \%$. With C8, after an initial period with high current value $(8 \mathrm{~mA})$, the current proved stable at $3 \mathrm{~mA}$ for more than 1 hour and then slightly decreased. An excellent faradaic yield of $90 \%$ was obtained. Finally, the study of $\mathbf{C 2}$ revealed that the initial current was remarkably high $(40 \mathrm{~mA})$, reflecting an outstanding activity but decreased rapidly to stabilize at $2 \mathrm{~mA}$ after $20 \mathrm{~min}$, and a faradaic yield of $70 \%$ was obtained. All together, these data identified $\mathbf{C 2}$ and $\mathbf{C 8}$ as among the best cobalt-bisterpyridyl catalysts for HER reported so far.

Inspection of the CV plots in Figure 2 suggests two classes of catalysts, C1 - C5 on one hand, and C6 - C8 on another hand, with different reaction mechanisms governing the hydrogen evolution. DFT calculations were used to provide insights into the catalytic mechanisms for HER by these new cobalt bisterpyridyl catalysts, exemplified by $\mathbf{C} \mathbf{1}$ and $\mathbf{C} \mathbf{8}$ and the proposed mechanisms are shown in Figure 5 and Figure 6, respectively. We have characterized the electronic structure of all the stationary points along the reaction path and calculated the one-electron reduction potentials of the electron transfer (ET) steps as well as the energies of the proton transfer (PT) steps. The term "concerted proton electron transfer (CPET)" is used generally to indicate that only the net free energy changes associated with addition of both a proton and an electron is considered, ignoring the detailed aspects associated with synchronicity and spatial proximity. Complex $\mathbf{C 1}$, referred here as $\mathbf{C 1}^{[2+]}$ has a doublet ground state at the M06-L level of theory that is $5.5 \mathrm{kcal} \mathrm{mol}^{-1}$ lower in energy that the high-spin quartet state. Its one-electron reduction is computed to occur at $E^{0}=-$ $0.72 \mathrm{~V}$ vs. $\mathrm{Fc} / \mathrm{Fc}^{+}$and leads to the formation of a $\mathrm{Co}^{\prime}$ species, $\mathrm{C1}^{[+]}$, in a triplet ground state. The two unpaired electrons are localized on the Co center (see Figure S28 A and B), and the added electron is found to reside primarily on the $\sigma^{*}\left(3 d z^{2}\right)$ orbital of the Co center. Subsequent reduction to $\mathbf{C 1}^{[0]}$ is computed to occur at $E^{0}=-1.76 \mathrm{~V}$ vs. $\mathrm{Fc} / \mathrm{Fc}^{+}$and leads to a quartet species that is almost degenerate with the doublet one (within $1.6 \mathrm{kcal} \mathrm{mol}^{-1}$ ) and its highest SOMO possesses an electron that is delocalized on the terpyridine ligand (Figure S28 C). The generation of hydrogen from the $\mathrm{C1}^{[+]}$state could proceed either through step-wise (ETPT or PTET) or concerted (CPET) pathways. In the former case of ETPT, the electron transfer step computed at $-1.76 \mathrm{~V}$ agrees relatively well with the experimental value of $-2.04 \mathrm{~V}$ and is followed by a protonation step (Gibbs free energy of $0.2 \mathrm{kcal} \mathrm{mol}^{-1}$ ) that results in a species $(\mathbf{C} 1-\mathbf{C H})^{[+]}$, with a protonated central pyridyl ring at the 4-position (Figures 5 and S29). The transition state barrier is $+13.2 \mathrm{kcal} \mathrm{mol}^{-1}$. In contrast, we find that protonation of the pyridyl-type $\mathrm{N}$ atom at the distal ring, leading to a cleavage of the Co-N bond distance is $10.5 \mathrm{kcal} \mathrm{mol}^{-1}$ less favorable and that it can be excluded. Moreover, a concerted pathway could as well be envisioned for the formation of $(\mathbf{C} 1-\mathbf{C H})^{[+]}$, proceeding virtually through the same potential $\left(E^{0}=-1.76 \mathrm{~V}\right)$. 


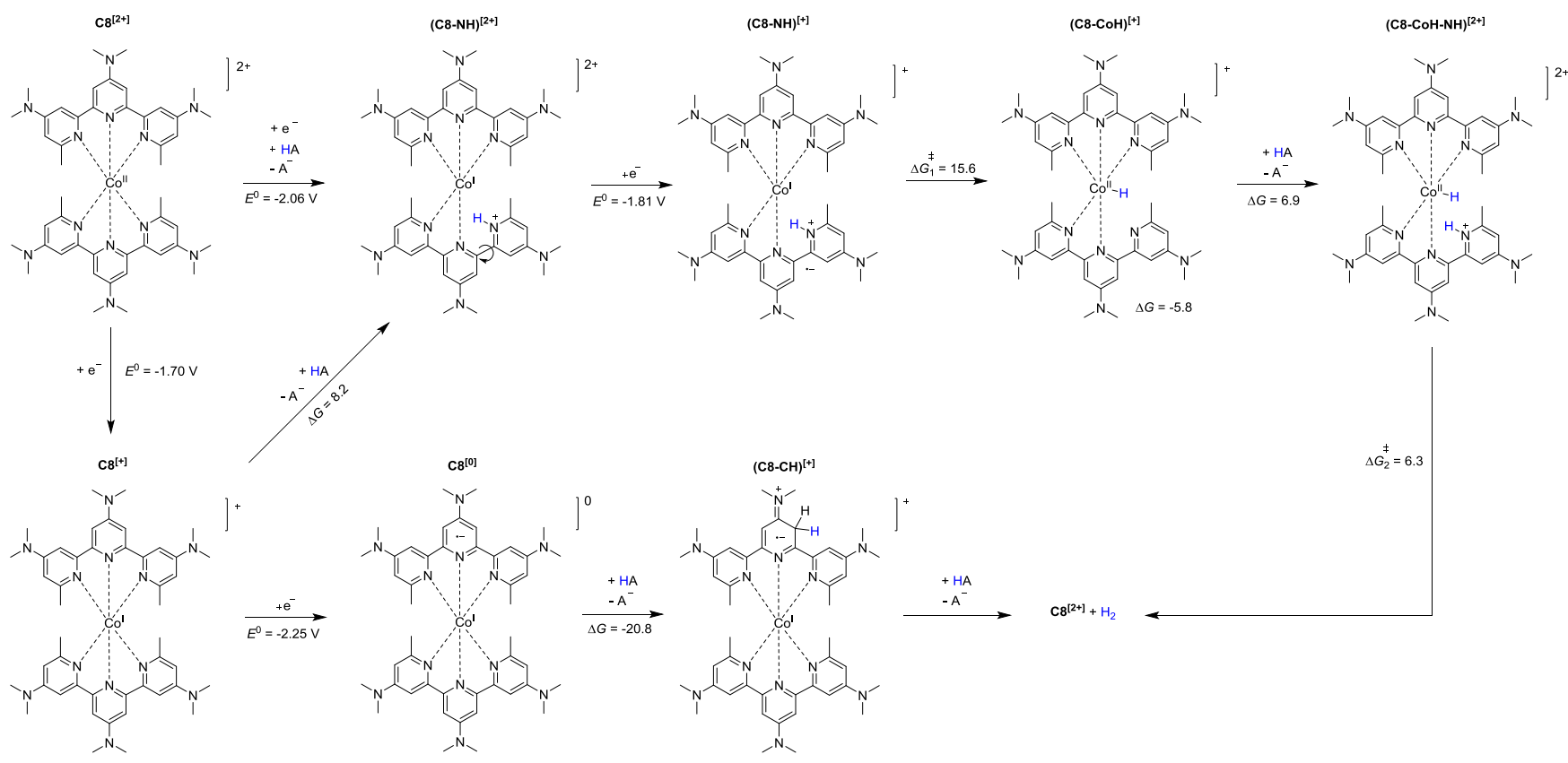

Figure 6. Proposed reaction mechanism for hydrogen evolution by complex $\mathbf{C 8}$. The relative Gibbs free energies of protonation $\left(\Delta G\right.$, kcal mol $\left.{ }^{-1}\right)$ are computed using the homoconjugated acetic acid couple and the standard one-electron reduction potentials $\left(E^{0}, \mathrm{~V}\right)$ are given $v s$. Fc/Fc.$\Delta G^{\ddagger}$ are the transition state barriers computed with an acetic acid molecule as an explicit proton source.

Protonation of the hydride by an acid source produces $\mathrm{H}_{2}$ in a facile step. Interestingly, if a step-wise PTET mechanism takes place directly from the $\mathbf{C 1}^{[+]}$state (bottom of Figure 5), the calculation would favor protonation at the distal pyridyl nitrogen atom giving rise to a $(\mathbf{C} 1-\mathrm{NH})^{[2+]}$ species, which is $7.2 \mathrm{kcal} \mathrm{mol}^{-1}$ lower in energy than the corresponding $(\mathbf{C} 1-\mathbf{C H})^{[2+]}$ formed by protonation at the 4-position of the central pyridyl carbon. Note that within $(\mathbf{C} 1-\mathbf{N H})^{[2+]}$ the cleavage of one $\mathrm{Co}-\mathrm{N}$ bond is accompanied by a flip of the protonated pyridyl ring by $\sim 30$ degrees out of the tpy plane. A transition state for this PT step was located with a barrier of $+14.8 \mathrm{kcal} \mathrm{mol}^{-1}$. However, the oneelectron reduction of the resulting $(\mathbf{C} 1-\mathbf{N H})^{[2+]}$ intermediate to $(\mathbf{C} 1-\mathrm{NH})^{[+]}$is computed to occur at $E^{0}=-1.05 \mathrm{~V}$ vs. $\mathrm{Fc} / \mathrm{Fc}^{+}$, which is too anodic as compared to the experimental CV data.

Thus, our DFT mechanistic studies on $\mathbf{C 1}$ complex indicate the HER to occur on the terpyridyl ligand, leaving the cobalt coordination sphere unchanged. We anticipate that the same mechanism is occurring in the case of complexes C2 - C5, based on their similar electrochemical behavior in the presence of acetic acid. It is worth noting that mechanisms involving active intermediates created upon protonation of the ligands rather than formation of metal hydrides have already been reported in the literature. ${ }^{[16-19]}$

As far as C8 is concerned, our DFT analysis finds a different operating mechanism, which is likely to also apply to $\mathbf{C 6}$ and $\mathbf{C 7}$ (see Figure 6). The initial complex, referred here as $\mathbf{C 8}^{[2+]}$ (high-spin quartet ground state), undergoes a one-electron reduction (calculated $E^{0}=-1.70 \mathrm{~V}$ vs. $\mathrm{Fc} / \mathrm{Fc}^{+}$) to $\mathrm{C}^{[+]}$, which is a Co' species with a triplet ground state. Calculations indicate that the following protonation step will occur at the pyridyl nitrogen of the distal ring, accompanied by a flip of that ring, resulting in $(\mathbf{C} 8-\mathrm{NH})^{[2+]}\left(\Delta G=+8.2 \mathrm{kcal} \mathrm{mol}^{-1}\right)$. Alternatively, the latter can also be obtained via a CPET pathway (calculated $E^{0}=-2.06 \mathrm{~V}$ vs. $\left.\mathrm{Fc} / \mathrm{Fc}^{+}\right)$. Further reduction to $(\mathbf{C} 8-\mathrm{NH})^{[+]}$occurs at a slightly more negative potential of $E^{0}=-1.81 \mathrm{~V}$, likely due to the reduced basicity of the protonated ligand. Analysis of the spin density of that reduced $(\mathbf{C} \mathbf{8}-\mathbf{N H})^{[+]}$species shows that the electron is mainly localized on the protonated distal pyridyl ring (Figure S30). Next, an intra-molecular proton transfer reaction takes place, resulting in the formation of a $\mathrm{Co}^{\prime \prime}(\mathrm{H})$ hydride species, $(\mathbf{C 8}-\mathbf{C o H})^{[+]}$, which is $5.8 \mathrm{kcal} \mathrm{mol}^{-1}$ lower in energy than the $(\mathbf{C 8}$ $\mathrm{NH})^{[+]}$intermediate. The computed reaction barrier for this process is $\Delta G^{\ddagger}=+15.6 \mathrm{kcal} \mathrm{mol}^{-1}$. The generation of hydrogen proceeds further by another protonation of the same pyridyl $\mathrm{N}$ atom $\left(\Delta G=+6.9 \mathrm{kcal} \mathrm{mol}^{-1}\right)$ which serves as a proton relay delivering a proton to the $\mathrm{Co}-\mathrm{H}$ bond. A transition state with a barrier of only $6.3 \mathrm{kcal} \mathrm{mol}^{-1}$ was located, towards releasing of $\mathrm{H}_{2}$ and regenerating the initial $\mathbf{C 8}^{[2+]}$ complex. Alternatively, direct protonation of the cobalt hydride by an acid source could lead to the $\mathrm{H}_{2}$ evolution. In addition, our calculations suggest that a reaction mechanism similar to that of $\mathbf{C} \mathbf{1}$ is likely to occur in the case of $\mathbf{C 8}$ only at very negative potentials $\left(E^{0}=-2.25 \mathrm{~V}\right.$ vs exp. $E^{0}=-2.49 \mathrm{~V}$ ) seen around the ligand-based wave in the experimental CV (Figure 2). The operating mechanism consists of two consecutive electron reduction steps to $\mathbf{C}^{\left[{ }^{[0]}\right.}$ species, followed by protonation at the central pyridyl ring at the 3position next to the $\mathrm{N}\left(\mathrm{CH}_{3}\right)_{2}$ group $\left(\Delta G=-20.8 \mathrm{kcal} \mathrm{mol}^{-1}\right)$. The resulting $(\mathbf{C} 8-\mathbf{C H})^{[+]}$intermediate is $19 \mathrm{kcal} \mathrm{mol}^{-1}$ more favorable than the corresponding (C8-NH) ${ }^{[+]}$obtained upon protonation of the distal pyridyl $\mathrm{N}$, and upon acid source will easily produce $\mathrm{H}_{2}$ and recover the $\mathbf{C} \mathbf{8}^{[2+]}$ catalyst.

In summary, new series of cobalt-bisterpyridyl systems were studied for HER, displaying different activities depending on the substituents on the ligand. Two complexes, C2 and C8 were selected and highlighted for their catalytic properties, in terms of stability, TON, TOF and overpotential. The CVs of 
complexes C1 - C8 revealed the existence of mechanistic differences, which have been rationalized by the present DFT computations. In particular, a ligand-based hydrogen evolution pathway is proposed for $\mathbf{C} \mathbf{1}-\mathbf{C 5}$, taking place at the central pyridyl ring and fully preserving the coordination sphere of the Co center. In contrast, the HER pathway for $\mathbf{C 6}$ - C8 invokes the formation of a cobalt hydride intermediate, formed from the initially protonated distal pyridyl nitrogen, that acts as a proton relay.

\section{Experimental Section}

General. The potentiostat used in this study was a SP 300 Bio-Logic potensiostat (Bio-Logic Science Instruments SAS). All CVs were recorded in an anaerobic glovebox. The electrochemical cell contained (i) a glassy carbon electrode as a working electrode $(\varnothing=1.0 \mathrm{~mm}$ ), (ii) a platinum wire as a counter electrode $(\varnothing=1 \mathrm{~mm})$ and (iii) a reference electrode made of a silver wire in a silver nitrate solution (10 $\mathrm{mM} \mathrm{AgNO}_{3}$ in acetonitrile with $0.1 \mathrm{M}$ TBAP electrolyte) isolated from the working solution by a vycor frit. The total volume of the solution was $3.0 \mathrm{~mL}$. The glassy carbon electrode was polished before each measurement with 1 $\mu \mathrm{m}$ diamond suspension. Dry acetonitrile was obtained using a MBraun Solvent Purification System.

Computational Details. All molecular geometries were fully optimized at

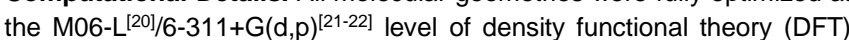
using the Gaussian 09 software package ${ }^{[23]}$ and the SMD implicitsolvation model $\left(\varepsilon=35.688\right.$ for acetonitrile). ${ }^{[24]}$ Quasi-relativistic

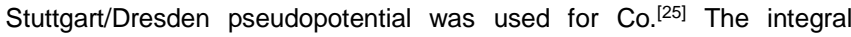
evaluation made use of the grid defined as "ultrafine" in G09. All stationary structures were characterized by vibrational frequency calculations, using the same level of theory as for the geometry optimizations. Thermochemical contributions were calculated using the ideal gas, rigid rotor, and harmonic oscillator approximations at a temperature of $298.15 \mathrm{~K}$. The protonation energies were computed with respect to the homoconjugated acetic acid couple, while an acetic acid molecule was used as an explicit proton source for the activation barrier calculations. Reduction potentials were calculated using the relation $E^{\circ}=$ $\left(-\Delta G^{\circ} / n F\right)-E_{\text {ref }}^{\circ}$, where $n$ is the number of transferring electrons, $F$ is Faraday's constant, $\Delta G^{\circ}$ is the Gibbs free energy of reduction, calculated for structures optimized in solution, and $E^{\circ}$ ref is the absolute reduction potential of the reference species (the ferrocenium/ferrocene couple $\left.\left(\mathrm{Fc}^{+} / \mathrm{Fc}\right)\right)$, computed at the same level of theory.

\section{Acknowledgements}

We acknowledge support from Foundation de l'Orangerie for individual Philanthropy and its donors. This work was supported by the French National Research Agency (ANR, Carbiored ANR12-BS07-0024-03; ANR, PhotoCarb ANR-16-CE05-0025-01; Grant "Labex DYNAMO" ANR-11-LABX-0011). P. H and H.-U. R acknowledge the Deutsche Forschungsgemeinschaft for support. The calculations were performed using the HPC resources of GENCI (TGCC) through Grant 2017-810082.

Keywords: Hydrogen • Catalysis • Terpyridines • Electrochemistry $\cdot$ DFT

\section{References}

[1] N. Kaeffer, M. Chavarot-Kerlidou, V. Artero, Acc. Chem. Res. 2015, 48, 1286-1295.

[2] D. Z. Zee, T. Chantarojsiri, J. R. Long, C. J. Chang, Acc. Chem. Res. 2015, 48, 2027-2036.

[3] N. Queyriaux, R. T. Jane, J. Massin, V. Artero, M. Chavarot-Kerlidou, Coordin. Chem. Rev. 2015, 304, 3-19.

[4] N. Elgrishi, M. B. Chambers, M. Fontecave, Chem. Sci. 2015, 6, 2522 2531.

[5] A. E. King, Y. Surendranath, N. A. Piro, J. P. Bigi, J. R. Long, C. J. Chang, Chem. Sci. 2013, 4, 1578-1587.

[6] C. Baffert, V. Artero, M. Fontecave, Inorg. Chem. 2007, 46, 1817-1824.

[7] M. Razavet, V. Artero, M. Fontecave, Inorg. Chem. 2005, 44, 47864795.

[8] N. Elgrishi, M. B. Chambers, V. Artero, M. Fontecave, Phys. Chem. Chem. Phys. 2014, 16, 13635-13644.

[9] N. Elgrishi, S. Griveau, M. B. Chambers, F. Bedioui, M. Fontecave Chem. Commun. 2015, 51, 2995-2998.

[10] S. Aroua, T.K. Todorova, P. Hommes, L.M. Chamoreau, H.U. Reissig, V. Mougel, M. Fontecave, Inorg. Chem. 2017, doi: 10.1021/acs.inorgchem.7b00595.

[11] V. Fourmond, P. A. Jacques, M. Fontecave, V. Artero, Inorg. Chem. 2010, 49, 10338-10347.

[12] B. D. McCarthy, D. J. Martin, E. S. Rountree, A. C. Ullman, J. L. Dempsey, Inorg. Chem. 2014, 53, 8350-8361.

[13] J. P. Bigi, T. E. Hanna, W. H. Harman, A. Chang, C. J. Chang, Chem Commun. 2010, 46, 958-960.

[14] M. Gomez-Mingot, J. P. Porcher, T. K. Todorova, T. Fogeron, C. MellotDraznieks, Y. Li, M. Fontecave, J. Phys. Chem. B 2015, 119, 1352413533.

[15] J. P. Porcher, T. Fogeron, M. Gomez-Mingot, E. Derat, L. M. Chamoreau, Y. Li, M. Fontecave, Angew. Chem. Int. Edit. 2015, 54, 14090-14093.

[16] V. Ganesan, D. Sivanesan, S. Yoon, Inorg. Chem. 2017, 56, 13661374.

[17] C. L. Pitman, O. N. Finster, A. J. Miller, Chem. Commun. 2016, 52, 9105-9108.

[18] D. P. Estes, D. C. Grills, J. R. Norton, J. Am. Chem. Soc. 2014, 136, 17362-17365

[19] K. Koshiba, K. Yamauchi, K. Sakai, Angew. Chem. Int. Edit. 2017, 56 4247-4251.

[20] Y. Zhao, D. G. Truhlar, J. Chem. Phys. 2006, 125, 194101-194118.

[21] A. D. Mclean, G. S. Chandler, J. Chem. Phys. 1980, 72, 5639-5648.

[22] R. Krishnan, J. S. Binkley, R. Seeger, J. A. Pople, J. Chem. Phys. 1980, 72, 650-654.

[23] M. J. Frisch, G. W. Trucks, H. B. Schlegel, G. E. Scuseria, M. A. Robb, J. R. Cheeseman, G. Scalmani, V. Barone, B. Mennucci, G. A Petersson, H. Nakatsuji, M. Caricato, X. Li, H. P. Hratchian, A. F. Izmaylov, J. Bloino, G. Zheng, J. L. Sonnenberg, M. Hada, M. Ehara, K Toyota, R. Fukuda, J. Hasegawa, M. Ishida, T. Nakajima, Y. Honda, O Kitao, H. Nakai, T. Vreven, J. A. Montgomery Jr., J. E. Peralta, F. Ogliaro, M. J. Bearpark, J. Heyd, E. N. Brothers, K. N. Kudin, V. N Staroverov, R. Kobayashi, J. Normand, K. Raghavachari, A. P. Rendell, J. C. Burant, S. S. lyengar, J. Tomasi, M. Cossi, N. Rega, N. J. Millam, M. Klene, J. E. Knox, J. B. Cross, V. Bakken, C. Adamo, J. Jaramillo, R. Gomperts, R. E. Stratmann, O. Yazyev, A. J. Austin, R. Cammi, C. Pomelli, J. W. Ochterski, R. L. Martin, K. Morokuma, V. G. Zakrzewski, G. A. Voth, P. Salvador, J. J. Dannenberg, S. Dapprich, A. D. Daniels, Ö. Farkas, J. B. Foresman, J. V. Ortiz, J. Cioslowski, D. J. Fox, Gaussian, Inc., Wallingford, CT, USA, 2009

[24] A. V. Marenich, C. J. Cramer, D. G. Truhlar, J. Phys. Chem. B 2009, 113, 6378-6396.

[25] M. Dolg, U. Wedig, H. Stoll, H. Preuss, J. Chem. Phys. 1987, 86, 866872. 